\title{
Host-mediated effects of phytonutrients in ruminants: A review ${ }^{1}$
}

\author{
J. Oh, ${ }^{*}$ E. H. Wall, $†$ D. M. Bravo,† and A. N. Hristov*2 \\ *Department of Animal Science, The Pennsylvania State University, University Park 16802 \\ †Pancosma S.A., CH-1218 Geneva, Switzerland
}

\begin{abstract}
Plants produce an extensive array of organic compounds derived from secondary metabolism that may be useful in animal nutrition because of their chemical makeup. These plant-derived bioactive compounds, also referred to as phytonutrients $(\mathrm{PN})$ or phytobiotics, have been shown to express antimicrobial activities against a wide range of bacteria, yeast, and fungi and have been investigated as rumen modifiers in ruminant nutrition. Studies have reported that PN may inhibit deamination of AA and methanogenesis in the rumen and shift fermentation toward propionate and butyrate. Most of the experiments, however, have been conducted in vitro, and responses have been highly variable and inconsistent in animal experiments. In addition, some studies have reported that PN had positive effects on productivity, although rumen fermentation was not affected. Other than antimicrobial effects in the gut, PN are known to bind specific receptors expressed in neurons, intestines, and other cells and exhibit related physiological effects in nonruminants. The receptormediated effects include immune responses, oxidative stress, and insulin secretion and activity. Some PN, due to their phenolic nature, are likely less susceptible to microbial degradation in the rumen and may exhibit activities postruminally, similar to their mode of action in nonruminant species. This opens a new area of research in ruminants, including effects of $\mathrm{PN}$ on the animal's immune system, postruminal nutrient use, and animal physiology. Although limited, studies with ruminants provide first evidence of PN's regulatory effects on the host responses. For example, PN were reported to regulate immune cells related to adaptive and innate immunity in challenged or nonchallenged dairy cows. Supplementation of PN reduced oxidative stress by decreasing lipid peroxidation and increasing endogenous antioxidants in ruminants. Additionally,
\end{abstract}

\footnotetext{
Received November 21, 2016.

Accepted February 21, 2017.

${ }^{1}$ Presented as part of the Non-Nutrition: The Future of Nutrition? Symposium at the ADSA-ASAS Joint Annual Meeting, Salt Lake City, Utah, July 2016.

${ }^{2}$ Corresponding author: anh13@psu.edu
}

insulin secretion and sensitivity were reportedly regulated by PN in dairy cows. The regulatory effects of PN on immunity may be beneficial for immune suppression and inflammation in dairy cows. In addition, PN could positively affect energy partitioning for milk production through their effects on insulin secretion and sensitivity. Further research is needed to elucidate the effect and mode of action of PN on immune function and animal energetics.

Key words: phytonutrient, immune response, insulin, dairy cow

\section{INTRODUCTION}

Plant-derived bioactive compounds, also referred to as phytonutrients $(\mathbf{P N})$, have shown a wide range of antimicrobial properties against bacteria, protozoa, and fungi and have been investigated as potential rumen modifiers in ruminants (Calsamiglia et al., 2007; Patra, 2012; Oh and Hristov, 2016). Studies have reported that PN shift rumen fermentation toward propionate and decrease ammonia concentration and methane production in the rumen (Hart et al., 2008; Klevenhusen et al., 2012). However, most research was based on in vitro batch or continuous culture studies, and results could not be replicated in experiments with live animals, especially with dairy cows (Benchaar et al., 2008a).

Studies with nonruminant species have shown that at low doses PN can trigger receptor-mediated host responses related to gastrointestinal health and host immunity (Furness et al., 2013). Various PN, with active ingredients such as eugenol, cinnamaldehyde, allicin, and capsaicin, activate mammalian transient receptor potential (TRP) channels that are expressed on neurons, the intestines, the pancreas, immune cells, and other tissues (Vriens et al., 2008; Holzer, 2011). Binding of the PN to TRP channels activates the cells and exhibits various physiological functions, including the release of neuropeptides and the activation of ion channels. Reportedly, PN regulated pro- or antiinflammatory responses by increasing or decreasing inflammatory cytokines, white blood cells, and oxidative stress in nonruminants (Zeng et al., 2015). In addition, pancreatic hormones, especially insulin secretion or 
sensitivity, were shown to be regulated by PN (van de Wall et al., 2005; Qin et al., 2010). In ruminants, recent findings demonstrated the physiological effects of PN on the host animal rather than on rumen microbes. Oh et al. (2013) reported that abomasal infusion of garlic oil, Curcuma, and Capsicum increased T helper cells related to the adaptive immunity without affecting the intestinal microbial populations in dairy cows. Furthermore, rumen-protected Capsicum decreased insulin secretion during a glucose tolerance test and alleviated acute phase immune responses in dairy cows challenged with LPS (Oh et al., 2017a,b). The goal of this review is to provide an overview of the effects of $\mathrm{PN}$ on rumen fermentation and discuss recent findings related to the regulatory effects of $\mathrm{PN}$ on immunity and insulin regulation in ruminant animals.

\section{EFFECTS OF PN ON RUMEN FERMENTATION AND PRODUCTIVITY}

\section{Rumen Fermentation}

It is well known that PN exhibit a wide range of antimicrobial effects against bacteria, protozoa, archaea, and fungi (Patra, 2012). The antimicrobial properties of PN are attributed to the hydrophobicity of their active compounds (Calsamiglia et al., 2007). The mode of action of PN such as terpenoids and tannins were discussed elsewhere (Calsamiglia et al., 2007; Patra and Saxena, 2011).

The effects of PN on rumen fermentation, including VFA, ammonia, and methane production, have been extensively studied (Benchaar et al., 2008a; Hart et al., 2008; Khiaosa-ard and Zebeli, 2013). Phytonutrients tended to decrease acetate and ammonia concentration, acetate to propionate ratio, and methane production and increased propionate in vitro (Klevenhusen et al., 2012). Results from the in vitro studies, however, have not been reproduced in vivo (Benchaar et al., 2008a; $\mathrm{Oh}$ and Hristov, 2016). Overall, PN doses tested in vitro have been much greater than physiologically acceptable application rates in vivo. According to metaanalyses, PN doses in vitro ranged from 0.03 to $500 \mathrm{~g} /$ $\mathrm{kg}$ of dietary DM (Klevenhusen et al., 2012), whereas doses used for in vivo studies ranged from 0.02 to 0.75 in small ruminants, 0.04 to 0.25 in beef cattle, and 0.01 to $0.43 \mathrm{~g} / \mathrm{kg}$ of dietary DM in dairy cows (Khiaosa-ard and Zebeli, 2013). Rumen fermentation responses were also not consistent among in vivo studies. Khiaosa-ard and Zebeli (2013) reported that PN were more effective in decreasing rumen acetate and ammonia concentration and methane production in small ruminants and beef cattle than dairy cows. For example, garlic oil (500 $\mathrm{mg} / \mathrm{kg}$ of $\mathrm{DM}$ ) decreased ruminal ammonia and in- creased propionate concentrations in sheep (Anassori et al., 2011) but had no effect $(250 \mathrm{mg} / \mathrm{kg}$ of DM) in dairy cows (Yang et al., 2007). Capsicum oleoresin (13-60 $\mathrm{mg} / \mathrm{kg}$ of DM) decreased ruminal acetate concentrations in beef cattle (Fandiño et al., 2008; RodríguezPrado et al., 2012), whereas no effect (9-38 mg/ $\mathrm{kg}$ of DM) was observed on rumen fermentation in dairy cows (Oh et al., 2015). It was speculated that, compared with dairy cows, the relatively lower rumen $\mathrm{pH}$ in beef cattle may enhance the effects of PN by increasing their hydrophobicity, which may increase their adverse effects on bacterial cell membranes (Cardozo et al., 2005; Calsamiglia et al., 2007).

\section{Animal Productivity}

Several studies have investigated the effects of PN on production in beef and dairy cattle. In general, production responses were not consistent among studies, likely due to differences in chemical properties of PN, doses, and animal species. For example, Yang et al. (2010) supplemented 400, 800, or 1,600 mg of cinnamaldehyde/d per head in a study with 70 yearling steers and observed that DMI and ADG were quadratically increased by the treatment during the first $28 \mathrm{~d}$. In dairy cows, supplementing cinnamaldehyde $(1 \mathrm{~g} / \mathrm{d}$ or $50 \mathrm{mg} / \mathrm{kg}$ of dietary DM) did not affect DMI, milk yield, or milk composition in crossover design experiments with 28-d periods (Benchaar et al., 2008b; Benchaar, 2016). A mixture of cinnamaldehyde and eugenol (525 mg/d per head) in a series of crossover and randomized block design experiments had no effect on productivity in dairy cows (Tekippe et al., 2013). Wall et al. (2014) reported that the same PN mixture decreased milk yield at 400 and $600 \mathrm{mg} / \mathrm{d}$ per head in multiparous cows, whereas milk yield was increased with 200 and $600 \mathrm{mg} / \mathrm{d}$ per head in primiparous cows. Also, DMI was increased by PN only in the primiparous cows. These studies suggested that production effects of PN may depend on parity in dairy cows. Dietary supplementation of Capsicum oleoresin $(250 \mathrm{mg} / \mathrm{d}$ per head) did not affect milk production of dairy cows in a study by Tager and Krause (2011). However, recent studies have reported positive effects of Capsicum oleoresin on cow productivity. Oh et al. (2015) observed increased milk and ECM yields with a solid form of Capsicum oleoresin $(250$ and $500 \mathrm{mg} / \mathrm{d}$ per head). Stelwagen et al. (2016) and Oh et al. (2017b) reported that rumen-protected Capsicum oleoresin (100 or $200 \mathrm{mg} / \mathrm{d}$ per head) increased milk yield and feed efficiency, respectively, in dairy cows.

Supplementation of PN in some studies with dairy cows increased milk production or feed efficiency at low doses (i.e., from about 4 to $38 \mathrm{mg} / \mathrm{kg}$ of dietary DM); similar concentrations had limited effects on rumen fer- 
mentation in vitro (Hart et al., 2008). In a study with dairy cows, low doses of PN had no effects on rumen fermentation (Oh et al., 2015). Therefore, it is plausible that low doses of PN may have positive effects on the host animal through postruminal mechanisms rather than effects on the rumen microbiota.

\section{EFFECTS OF PN ON HOST RESPONSES}

The original interest in $\mathrm{PN}$ in ruminant nutrition focused on their modulatory effects on the rumen microbiota and fermentation (Calsamiglia et al., 2007; Khiaosa-ard and Zebeli, 2013). In nonruminant species, however, PN have been shown to trigger an array of positive host responses as well as effects on the intestinal microbiota. Specifically, various $\mathrm{PN}$ have been known to exhibit regulatory effects on immunity, hormone regulation, and neurology (Furness et al., 2013; Zeng et al., 2015). Similar effects of PN are expected to be exhibited in ruminants if $\mathrm{PN}$ bypass ruminal microbial degradation (or are supplemented to the diet in a rumen-protected form).

\section{Rumen Stability of PN}

It is known that some phenolic PN are resistant to microbial degradation in the rumen. According to Franz et al. (2010), approximately $60 \%$ of menthone, thymol, and carvacrol was recovered after $24 \mathrm{~h}$ of incubation with rumen fluid in a continuous culture study. Because the passage rate of the liquid phase of rumen contents can be as high as 20\%/h in dairy cows (Hristov et al., 2003), it is likely that PN associated with rumen liquid have a short retention time in the rumen. In a recent study, we measured rumen bypass rate of capsaicin and dihydrocapsaicin using ruminal pulse dose and Cr-EDTA as a liquid phase marker (Oh et al., 2016). The bypass rate of capsaicin and dihydrocapsaicin was between 15 and $33 \%$ depending on the dose amount (250, 500, or 1,000 mg of Capsicum oleoresin).

\section{Immune Responses}

The immune responses to $\mathrm{PN}$ in nonruminant animals have been thoroughly investigated and reported (Zeng et al., 2015). The mode of action of PN on the immune system varies depending on their chemical properties. It has been demonstrated that PN exhibit receptor-mediated responses related to physiological effects such as gastrointestinal health and host immunity (Furness et al., 2013). Some PN activate the TRP channels, which are expressed on neurons, the intestines, the pancreas, and immune cells in mammalian tissues and serve as receptors for the PN (Holzer, 2011). This means that PN could bind to and enable TRP channels to act as secondary transducers of cell activation or ion transporters (Figure 1). For example, eugenol binds to TRPV1 and TRPV3 and exhibits antiinflammatory and antioxidant properties, cinnamaldehyde is mediated with TRPA1 and can serves as an immune enhancer, and allicin (an active compound in garlic) activates TRPA1 and TRPV1 (Vriens et al., 2008). Reportedly, capsaicin binds to TRPV1 and modulates immune responses and improves mucosal blood flow in the gastrointestinal tract (Holzer, 2011). Binding of capsaicin to TRPV1 could modify immune cells, including macrophages, neutrophils, T lymphocytes, and B lymphocytes, by stimulating or inhibiting cytokines and antibodies (Franco-Penteado et al., 2006; Takano et al., 2007; Nevius et al., 2012). Capsaicin could directly act on immune cells through TRPV1 expressed on the cell membrane in mammals (Cortright and Szallasi, 2004). Capsaicin can also indirectly affect immune cells by binding to TRPV1 on afferent neurons that regulate the release of neuropeptides such as calcitonin gene-related peptide (CGRP), substance $\mathrm{P}$, and tachykinin (Tsuji and Aono, 2012). It is known that CGRP plays an antiinflammatory role, and substance $\mathrm{P}$ and tachykinin are associated with vasodilation, plasma extravasation, and proinflammatory actions (Zimmerman et al., 1992; Pennefather et al., 2004).

In nonruminant animals, PN have exhibited proinflammatory effects by increasing or stimulating immune cells and proinflammatory cytokines. Garlic was also shown to induce proliferation of immune cells such as peripheral blood mononuclear cells and T cells in humans and rats (Salman et al., 1999; Colić et al., 2002). Allicin increased proinflammatory cytokine production and the absolute numbers of $\mathrm{T}$ helper cells, dendritic cells, and macrophages in mice infected by a parasite, Plasmodium yoelii (Feng et al., 2012). Wang et al. (2011) reported that dietary supplementation of fermented garlic increased the proportion of cluster of differentiation (CD) $4^{+}$in T lymphocytes in challenged or nonchallenged pigs with LPS. Lee et al. (2011) demonstrated that a PN mixture increased the effectiveness of a protein vaccine in chickens challenged with a parasite. In that study, diet supplementation of Capsicum and curcuma increased lymphocyte proliferation and blood $\mathrm{CD} 4^{+}$cells in vaccinated and challenged chickens. Capsaicin increased neutrophil production in the bone marrow of rats (Franco-Penteado et al., 2006), and curcumin alone inhibited tumor formation by increasing $\mathrm{CD}^{+} \mathrm{T}$ cells in the intestinal mucosa of mice (Churchill et al., 2000).

Data on the physiological effects of PN in ruminants are limited (Table 1). Ahmed et al. (2015) reported in goats that various concentrations of green tea by-prod- 
ucts $(0,0.5,1.0$, and $2.0 \%$ of $\mathrm{DM})$ increased the proliferation of $\mathrm{T}$ and $\mathrm{B}$ cells in spleen cells activated with concanavalin A and LPS. Catechins, the main active compounds in green tea by-products, exhibited proinflammatory effects in the spleen of goats, although the mode of action could not be elucidated in that study. In dairy cows, direct infusion of garlic oil, Curcuma oleoresin, and Capsicum oleoresin into the abomasum ( $2 \mathrm{~g} / \mathrm{d}$ per head) increased CD $4^{+}$cells (Oh et al., 2013). All treatments in that experiment also tended to double the proportion of $\mathrm{CD} 4^{+}$coexpressed CD25 $\alpha$ (an activation molecule on $\mathrm{T}$ lymphocytes), which indicated that activated $\mathrm{T}$ helper cells were facilitated by $\mathrm{PN}$. In the same experiment, garlic oil slightly increased neutrophil to lymphocyte ratio, which is indicative of an acute stress response (Weiss and Wardrop, 2010). In a follow-up experiment, we reported that dietary Capsicum oleoresin increased the numbers of neutrophils and eosinophils and the neutrophil to lymphocyte ratio in peripheral blood in dairy cows (Oh et al., 2015). In addition, phagocytosis of neutrophils was also increased by Capsicum oleoresin. In that experiment, dietary Capsicum oleoresin facilitated immune cells related to acute phase immune responses (Oh et al., 2015). The observed proinflammatory effects of PN may stimulate immune responses, which could be beneficial for dairy cows experiencing immune suppression (e.g., during the transition period and early lactation; Sordillo and Aitken, 2009).

Interestingly, PN have exhibited antiinflammatory effects as well, such as decreased proinflammatory cytokines and acute phase immune responses. Kuo et al. (2011) reported that garlic oil decreased neutrophil infiltration by decreasing the expression of adhesion molecules in rats. Curcumin supplementation (300 or $400 \mathrm{mg} / \mathrm{kg}$ of DM) improved intestinal mucosal barrier integrity by decreasing intraepithelial lymphocytes, toll-like receptor 4 , interleukin-1 $\beta$, and tumor necrosis factor- $\alpha$ in piglets challenged with Escherichia coli (Xun et al., 2015). In that experiment, the antiinflammatory effects of curcumin resulted in improved feed efficiency. Capsicum exhibited antiinflammatory effects in pigs challenged with Escherichia coli by decreasing markers of acute phase immune responses such as haptoglobin and neutrophils in blood (Liu et al., 2013b). A mixture of Capsicum and turmeric decreased gut lesion and inflammatory cytokines and increased BW in chickens challenged with necrotic enteritis (Lee et al., 2013). In dairy cows, a mixture of curcumin, carnosic acid, cinnamaldehyde, and eugenol improved udder health by decreasing SCC in milk (Hashemzadeh-Cigari et al., 2014). Again in dairy cows, dietary supplementation

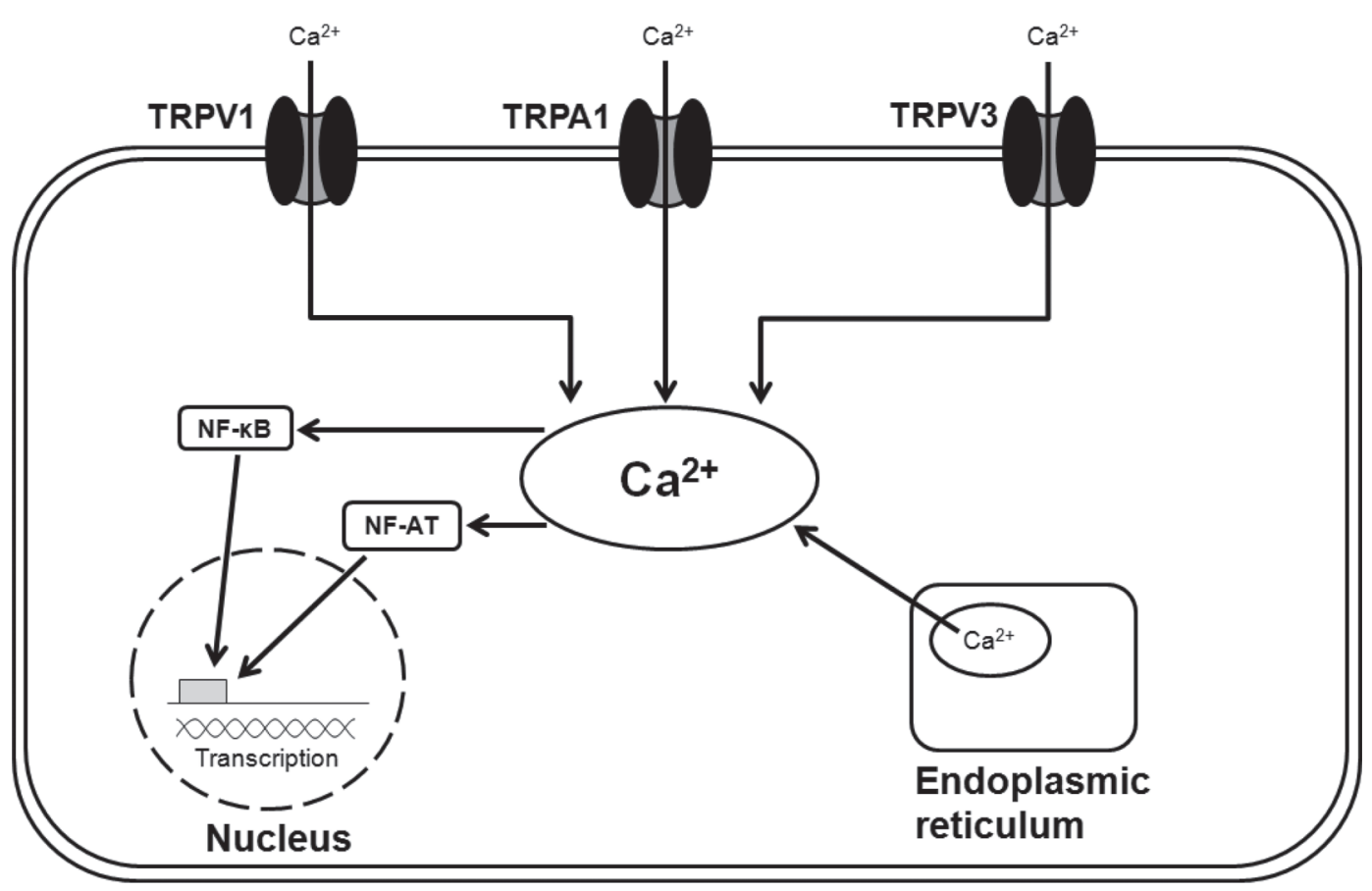

Figure 1. A diagram representing $\mathrm{Ca}^{2+}$ signal activated by phytonutrients through transient receptor potential (TRP) channels in immune cells. TRPV1 is activated by eugenol, capsaicin, and allicin; TRPA1 is activated by allicin and cinnamaldehyde; and TRPV3 is activated by eugenol (Vriens et al., 2008). Binding of phytonutrients to TRP on the membrane induces $\mathrm{Ca}^{2+}$ influx. Intracellular $\mathrm{Ca}^{2+}$ allows transcription factors such as nuclear factor (NF)- $\mathrm{B}$ and nuclear factor of activated T-cells (NF-AT) to enter the nucleus (Berridge et al., 2000). Release of $\mathrm{Ca}^{2+}$ from the internal stores in the endoplasmic reticulum can be stimulated by the activation of the TRP channels (Gees et al., 2010). 
OH ET AL.

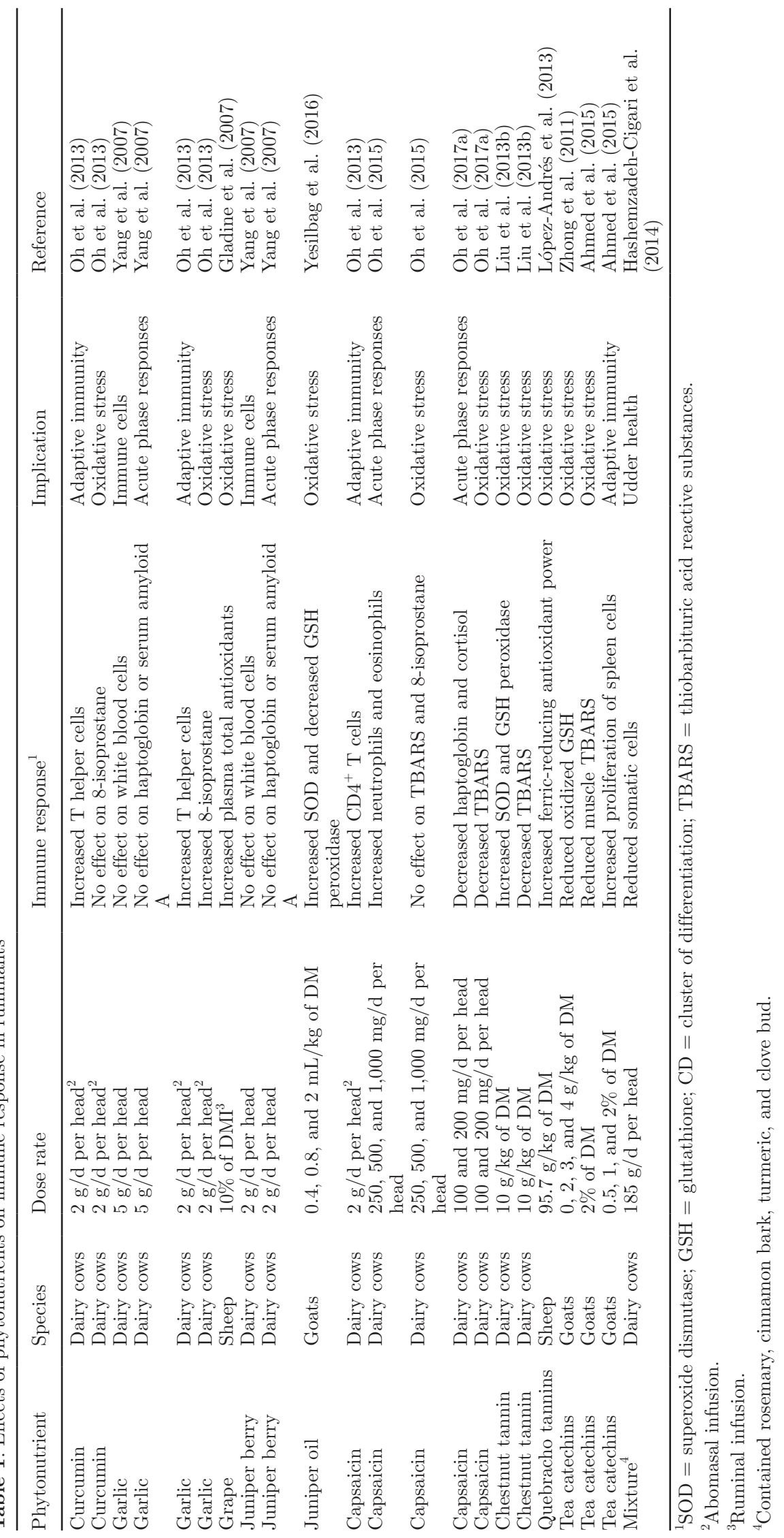


of rumen-protected Capsicum decreased blood concentrations of haptoglobin and cortisol induced by LPS challenge (Oh et al., 2017a).

The immune-regulatory (i.e., pro- or antiinflammatory) effects of PN may depend on the immune challenge status of the experimental animals. Liu et al. (2012) reported that anethole, Capsicum, carvacrol, eugenol, garlic, cinnamaldehyde, and turmeric increased proinflammatory cytokines such as tumor necrosis factor and interleukin-1 in nonactivated porcine macrophages. However, the proinflammatory cytokines were decreased by the PN in macrophages challenged with LPS. In our studies with dairy cows, as indicated previously, Capsicum supplementation increased immune cells such as $\mathrm{T}$ helper cells and neutrophils in nonchallenged cows but decreased inflammatory responses, including haptoglobin and oxidative stress, in cows challenged with LPS (Oh et al., 2013; Oh et al., 2017a). Additionally, the immunoregulatory effects of PN may depend on dose. A low dose of capsaicin (1 mg/kg of BW per day) increased an antiinflammatory neuropeptide, CGRP, in rats (Demirbilek et al., 2004). In contrast, a high dose (150 mg/kg of BW per day) decreased the concentration of CGRP in blood. Nevius et al. (2012) demonstrated dose-dependent immunoregulatory effects of capsaicin on $\mathrm{T}$ cells in nonobese diabetic mice. Orally dosed capsaicin $(10 \mu \mathrm{g} /$ head; pulse dosed twice at 9 and $10 \mathrm{wk}$ of age) decreased $\mathrm{T}$ cell proliferation in pancreatic lymph nodes, whereas the control $(0 \mu \mathrm{g})$, lower $(0.1$ or $1 \mu \mathrm{g})$, and higher $(25$ or $50 \mu \mathrm{g} /$ head) doses did not affect the $\mathrm{T}$ cells. In dairy cows, Oh et al. (2015) observed that low and medium doses of Capsicum oleoresin were more effective than the highest dose in increasing neutrophil activity and counts.

\section{Oxidative Stress}

It is well known that PN can serve as antioxidants by reducing reactive oxygen species (Amorati et al., 2013). As an example, 1 molecule of capsaicin scavenges 2 peroxyl radicals using its phenolic hydroxyl group (Okada et al., 2010). In addition, phenolic compounds have been reported to increase endogenous antioxidants, including superoxide dismutase (SOD), catalase (CAT), and glutathione (GSH; Masella et al., 2005). Superoxide dismutase serves as the first line of defense against reactive oxygen species and catalyzes the reduction of superoxide $\left(\mathrm{O}^{2 \bullet-}\right)$ to hydrogen peroxide $\left(\mathrm{H}_{2} \mathrm{O}_{2}\right)$ and $\mathrm{O}_{2}$; $\mathrm{H}_{2} \mathrm{O}_{2}$ is converted to water and oxygen by CAT. In addition, GSH reduces $\mathrm{H}_{2} \mathrm{O}_{2}$ to water through $\mathrm{GSH}$ peroxidase (Sen and Chakraborty, 2011).

Plant secondary metabolites are subject to detoxification in vivo by phase I, II, and III metabolisms, which include hydrolytic biotransformation, conjuga- tion reactions, and transporter-mediated efflux into the gut lumen or bile, respectively (Gurley, 2011). Due to the detoxifications, concentration of exogenous phenolic compounds in plasma or tissue generally is lower than that of endogenous antioxidants in vivo (Masella et al., 2005). This may explain why limited effects of $\mathrm{PN}$ have been observed on oxidative status in animal studies. Interestingly, it has been reported that phenolic PN could induce upregulations in genes and transcription factors related to the endogenous antioxidants, which includes aryl hydrocarbon receptor and nuclear factor E2 related factor (Seymour et al., 2013).

Garlic oil has been known to scavenge free radicals and reduce lipid peroxidation (Mirunalini et al., 2010). Nencini et al. (2010) reported increases in GSH and CAT levels with orally administered garlic homogenates (250 $\mathrm{mg} / \mathrm{kg}$ of BW) in rats with liver injury. Dietary curcumin $(0.2 \%$ of $\mathrm{DM})$ and capsaicin $(0.015 \%$ of $\mathrm{DM})$ reduced serum concentration of thiobarbituric acid reactive substances (TBARS) in rats with experimentally induced oxidative stress (Manjunatha and Srinivasan, 2006). These results indicated that curcumin and capsaicin inhibited lipid oxidation because TBARS are formed as a byproduct of lipid peroxidation. In the same experiment, curcumin and capsaicin supplementation lowered liver lipid peroxide level and liver enzymes such as alanine aminotransferase, aspartate aminotransferase, and lactate dehydrogenase, which suggested that those PN inhibited the hepatotoxicity and ameliorated the damage of the liver caused by induced oxidative stress (Senior, 2012). Hassan et al. (2012) experimentally induced liver injury in rats and observed that activities of endogenous antioxidants (including SOD, CAT, and GSH) in the liver tissue of the rats were increased by oral treatment of capsaicin. Abdel-Salam et al. (2012) also found that intragastric and intraperitoneal administration of capsaicin increased GSH in the brain, liver, and lungs of rats challenged with LPS.

The effects of PN on oxidative status have also been reported in studies with ruminants. Quebracho tannins $(95.7 \mathrm{~g} / \mathrm{kg}$ of $\mathrm{DM})$ increased ferric-reducing antioxidant power in the liver and blood of sheep, indicating enhanced antioxidant capacity (López-Andrés et al., 2013). Zhong et al. (2011) also reported that dietary tea catechins $(0,2,000,3,000$, or $4,000 \mathrm{mg} / \mathrm{kg}$ of DM) improved antioxidant status by reducing oxidized GSH in the blood of goats. This is in line with Ahmed et al. (2015), who observed antioxidative effects of dietary tea catechins (included in the diet at $2 \%$ of DM) manifested by decreased TBARS in gluteus medius muscles in goats. Phenolic compounds reportedly increase endogenous antioxidants in ruminants. In recent studies, juniper oil (0.4-2 mL/ $\mathrm{kg}$ of DM, containing $89.7 \%$ $\alpha$-pinene) increased activity of SOD in growing goats 
(Yesilbag et al., 2016), and a blend of herb powders (Woodfordia fruticosa, Solanum nigrum, and Trigonella foenum-graecum) containing hydrolysable tannins, steroidal saponins, and glycoalkaloids increased the activity of GSH peroxidase, CAT, and glutathioneS-transferase in the blood of goats (Choubey et al., 2016). In dairy cows, the effects of $\mathrm{PN}$ on oxidative stress are not consistent, and data are limited. Oh et al. (2013) reported that abomasal infusion of garlic oil $(2 \mathrm{~g} / \mathrm{d}$ per head) increased blood concentrations of a byproduct of lipid oxidation (8-isoprostane), whereas Curcuma and Capsicum had no effect on the oxidative stress markers. These results indicated that a high dose of garlic oil could have deleterious effects by increasing oxidative stress in dairy cows, although it is known as an antioxidant (Lambert and Elias, 2010). Dietary supplementation of Capsicum also did not affect oxidative stress markers in dairy cows (Oh et al., 2015). When cows were challenged with LPS, blood concentrations of TBARS were decreased by rumen-protected Capsicum supplementation (Oh et al., 2017a). Hashemzadeh-Cigari et al. (2015) also reported that a mixture of PN including rosemary, cinnamon bark, turmeric, and clove bud decreased blood TBARS concentration postpartum in dairy cows. Liu et al. (2013a) reported that chestnut tannins (mainly hydrolysable tannins) decreased an oxidative stress marker, malondialdehyde, and increased endogenous antioxidant enzymes such as SOD and GSH peroxidase in the blood and liver of transition cows.

\section{Hormone Regulation}

The islet hormones, insulin and glucagon, are critical in maintaining glucose homeostasis in blood in farm animals and other species. Hyperglycemia stimulates secretion of insulin from the islets of Langerhans; in turn, glucose is stored in the liver as glycogen. It is known that the secretion and regulation of insulin and glucagon are controlled by the nervous system (Osundiji and Evans, 2013). Innervation of the pancreas independently enables the islets to alter hormone release. Early studies have shown that stimulation of the vagus nerves regulated insulin secretion in vitro (Kaneto et al., 1967). In addition, the brain is able to systemically control hormone regulation of the pancreas (Osundiji and Evans, 2013). Consequently, the effects of PN activating TRP channels on hormone regulation in the pancreas have been investigated in studies with nonruminants (Holzer, 2011). Cinnamon extract containing cinnamaldehyde decreased the development of insulin resistance and increased the expression of glucose transporter 4 and glucose uptake in rats and in vitro
(Sheng et al., 2008; Qin et al., 2010). Nishiyama et al. (2005) reported that dietary inclusion of curcuminoids (turmeric extracts) decreased blood glucose concentration in type 2 diabetic mice and demonstrated that curcuminoids exhibited the hypoglycemic effects by activating peroxisome proliferator-activated receptor- $\gamma$, a nuclear receptor regulating fatty acid storage (Tyagi et al., 2011). Garlic also decreased glucose concentration in diabetic rats, although it was not clear whether the hypoglycemic effect resulted from enhanced insulin secretion from $\beta$-cells or from insulin sensitivity (Thomson et al., 2007). Unlike turmeric and garlic, capsaicin decreased insulin levels during glucose tolerance tests in rats, whereas blood glucose concentration was not affected (van de Wall et al., 2005, 2006). In human subjects, regular consumption of cayenne pepper containing capsaicin lowered insulin but did not affect postprandial blood glucose concentration (Ahuja et al., 2006). The inhibitory effect of capsaicin on insulin may be exhibited via CGRP, which is known to decrease insulin secretion by the pancreas (Pettersson and Ahrén, 1990; Tanaka et al., 2013). Capsaicin treatments reportedly increased plasma CGRP concentration in rats and human subjects (Demirbilek et al., 2004; van Oosterhout et al., 2015).

Hashemzadeh-Cigari et al. (2015) reported increased insulin sensitivity in dairy cows fed a mixture of PN including rosemary, cinnamon bark, turmeric, and clove bud. In that experiment, insulin sensitivity was measured by a quantitative insulin-sensitivity check index. Duodenal administration of quercetin twice daily (18 $\mathrm{mg} / \mathrm{kg}$ of $\mathrm{BW}$ ) in dairy cows decreased glucose and increased insulin concentrations, indicating that the flavonoid quercetin exhibited a hypoglycemic effect in the intestine (Gohlke et al., 2013). In another experiment with dairy cows, dietary supplementation of Capsicum decreased serum insulin without affecting glucose concentration during a glucose tolerance test (Oh et al., 2017b), which is in line with the results in rats and human subjects (Ahuja et al., 2006; van de Wall et al., 2006). Insulin plays an important role in energy partitioning in lactating dairy cows (De Koster and Opsomer, 2013). Although skeletal and muscle tissues are insulin dependent, glucose uptake in the mammary gland relies mainly on glucose transporter 1 , which is not dependent on insulin (Zhao and Keating, 2007). Thus, glucose supply to the mammary gland can vary according to insulin sensitivity of the insulin-dependent tissues or insulin secretion from the pancreas. Therefore, it is plausible that $\mathrm{PN}$, through their regulatory effects on insulin sensitivity or secretion, may redirect glucose for lactose synthesis and milk production in dairy cows (Oh et al., 2017b). 


\section{CONCLUSIONS}

Phytonutrients have been studied for their potential as rumen fermentation modifiers, primarily because of their antimicrobial effects. However, ruminal responses to PN have been inconsistent. Recent studies provided evidence that PN exhibit receptor-mediated physiological effects in the host animals, including effects on immunity, oxidative stress, and insulin regulation. The regulatory effects of PN on cytokines, acute phase proteins, blood immune cells, and oxidative stress status, including lipid peroxidation and endogenous antioxidants, may be beneficial for immune suppression and inflammation disease in dairy cows. In addition, PN, through their effects on insulin secretion and sensitivity, could positively affect energy partitioning for milk production. Initial data are encouraging, but PN have to be assessed in long-term experiments to fully elucidate their physiological effects in lactating dairy cows.

\section{ACKNOWLEDGMENTS}

The authors thank Pancosma S.A. (Geneva, Switzerland) for sponsoring The Future of Nutrition Symposium at the ADSA-ASAS Joint Annual Meeting, Salt Lake City, Utah, July 2016.

\section{REFERENCES}

Abdel-Salam, O. M., R. F. Abdel-Rahman, A. A. Sleem, and A. R. Farrag. 2012. Modulation of lipopolysaccharide-induced oxidative stress by capsaicin. Inflammopharmacology 20:207-217.

Ahmed, S. T., J. W. Lee, H. S. Mun, and C. J. Yang. 2015. Effects of supplementation with green tea by-products on growth performance, meat quality, blood metabolites and immune cell proliferation in goats. J. Anim. Physiol. Anim. Nutr. (Berl.) 99:1127-1137.

Ahuja, K. D., I. K. Robertson, D. P. Geraghty, and M. J. Ball. 2006. Effects of chili consumption on postprandial glucose, insulin, and energy metabolism. Am. J. Clin. Nutr. 84:63-69.

Amorati, R., M. C. Foti, and L. Valgimigli. 2013. Antioxidant activity of essential oils. J. Agric. Food Chem. 61:10835-10847.

Anassori, E., B. Dalir-Naghadeh, R. Pirmohammadi, A. Taghizadeh, S. Asri-Rezaei, M. Maham, S. Farahmand-Azar, and P. Farhoomand. 2011. Garlic: A potential alternative for monensin as a rumen modifier. Livest. Sci. 142:276-287.

Benchaar, C. 2016. Diet supplementation with cinnamon oil, cinnamaldehyde, or monensin does not reduce enteric methane production of dairy cows. Animal 10:418-425.

Benchaar, C., S. Calsamiglia, A. V. Chaves, G. R. Fraser, D. Colombatto, T. A. McAllister, and K. A. Beauchemin. 2008a. A review of plant-derived essential oils in ruminant nutrition and production. Anim. Feed Sci. Technol. 145:209-228.

Benchaar, C., T. A. McAllister, and P. Y. Chouinard. 2008b. Digestion, ruminal fermentation, ciliate protozoal populations, and milk production from dairy cows fed cinnamaldehyde, quebracho condensed tannin, or Yucca schidigera saponin extracts. J. Dairy Sci. 91:4765-4777.

Berridge, M. J., P. Lipp, and M. D. Bootman. 2000. The versatility and universality of calcium signalling. Nat. Rev. Mol. Cell Biol. $1: 11-21$.
Calsamiglia, S., M. Busquet, P. W. Cardozo, L. Castillejos, and A. Ferret. 2007. Invited review: Essential oils as modifiers of rumen microbial fermentation. J. Dairy Sci. 90:2580-2595.

Cardozo, P. W., S. Calsamiglia, A. Ferret, and C. Kamel. 2005. Screening for the effects of natural plant extracts at different $\mathrm{pH}$ on in vitro rumen microbial fermentation of a high-concentrate diet for beef cattle. J. Anim. Sci. 83:2572-2579.

Choubey, M., A. K. Pattanaik, S. Baliyan, N. Dutta, S. E. Jadhav, and K. Sharma. 2016. Dietary supplementation of a novel phytogenic feed additive: Effects on nutrient metabolism, antioxidant status and immune response of goats. Anim. Prod. Sci. 56:1612-1621.

Churchill, M., A. Chadburn, R. T. Bilinski, and M. M. Bertagnolli. 2000. Inhibition of intestinal tumors by curcumin is associated with changes in the intestinal immune cell profile. J. Surg. Res. $89: 169-175$.

Colić, M., D. Vucević, V. Kilibarda, N. Radicević, and M. Savić. 2002. Modulatory effects of garlic extracts on proliferation of T-lymphocytes in vitro stimulated with concanavalin A. Phytomedicine 9:117-124.

Cortright, D. N., and A. Szallasi. 2004. Biochemical pharmacology of the vanilloid receptor TRPV1. An update. Eur. J. Biochem. 271:1814-1819.

De Koster, J. D., and G. Opsomer. 2013. Insulin resistance in dairy cows. Vet. Clin. North Am. Food Anim. Pract. 29:299-322.

Demirbilek, S., M. O. Ersoy, A. Karaman, N. Gürbüz, N. Bayraktar, and M. Bayraktar. 2004. Small-dose capsaicin reduces systemic inflammatory responses in septic rats. Anesth. Analg. 99:1501-1507.

Fandiño, I., S. Calsamiglia, A. Ferret, and M. Blanch. 2008. Anise and capsicum as alternatives to monensin to modify rumen fermentation in beef heifers fed a high concentrate diet. Anim. Feed Sci. Technol. 145:409-417.

Feng, Y., X. Zhu, Q. Wang, Y. Jiang, H. Shang, L. Cui, and Y. Cao. 2012. Allicin enhances host pro-inflammatory immune responses and protects against acute murine malaria infection. Malar. J. 11:268.

Franco-Penteado, C. F., I. A. De Souza, C. S. Lima, S. A. Teixeira, M. N. Muscara, G. De Nucci, and E. Antunes. 2006. Effects of neonatal capsaicin treatment in the neutrophil production, and expression of preprotachykinin-I and tachykinin receptors in the rat bone marrow. Neurosci. Lett. 407:70-73.

Franz, C., K. H. C. Baser, and W. Windisch. 2010. Essential oils and aromatic plants in animal feeding-A European perspective. A review. Flavour Fragrance J. 25:327-340.

Furness, J. B., L. R. Rivera, H. J. Cho, D. M. Bravo, and B. Callaghan. 2013. The gut as a sensory organ. Nat. Rev. Gastroenterol. Hepatol. 10:729-740.

Gees, M., B. Colsoul, and B. Nilius. 2010. The role of transient receptor potential cation channels in Ca2+ signaling. Cold Spring Harb. Perspect. Biol. 2:a003962.

Gladine, C., E. Rock, C. Morand, D. Bauchart, and D. Durand. 2007. Bioavailability and antioxidant capacity of plant extracts rich in polyphenols, given as a single acute dose, in sheep made highly susceptible to lipoperoxidation. Br. J. Nutr. 98:691-701.

Gohlke, A., C. J. Ingelmann, G. Nurnberg, J. M. Weitzel, H. M. Hammon, S. Gors, A. Starke, S. Wolffram, and C. C. Metges. 2013. Influence of 4-week intraduodenal supplementation of quercetin on performance, glucose metabolism, and mRNA abundance of genes related to glucose metabolism and antioxidative status in dairy cows. J. Dairy Sci. 96:6986-7000.

Gurley, B. J. 2011. Emerging technologies for improving phytochemical bioavailability: Benefits and risks. Clin. Pharmacol. Ther. 89:915-919.

Hart, K. J., D. R. Yáñez-Ruiz, S. M. Duval, N. R. McEwan, and C. J. Newbold. 2008. Plant extracts to manipulate rumen fermentation. Anim. Feed Sci. Technol. 147:8-35.

Hashemzadeh-Cigari, F., G. R. Ghorbani, M. Khorvash, A. Riasi, A. Taghizadeh, and Q. Zebeli. 2015. Supplementation of herbal plants differently modulated metabolic profile, insulin sensitivity, and oxidative stress in transition dairy cows fed various extruded oil seeds. Prev. Vet. Med. 118:45-55. 
Hashemzadeh-Cigari, F., M. Khorvash, G. R. Ghorbani, M. Kadivar, A. Riasi, and Q. Zebeli. 2014. Effects of supplementation with a phytobiotics-rich herbal mixture on performance, udder health, and metabolic status of Holstein cows with various levels of milk somatic cell counts. J. Dairy Sci. 97:7487-7497.

Hassan, M. H., M. Edfawy, A. Mansour, and A. A. Hamed. 2012. Antioxidant and antiapoptotic effects of capsaicin against carbon tetrachloride-induced hepatotoxicity in rats. Toxicol. Ind. Health $28: 428-438$.

Holzer, P. 2011. Transient receptor potential (TRP) channels as drug targets for diseases of the digestive system. Pharmacol. Ther. 131:142-170

Hristov, A. N., S. Ahvenjarvi, T. A. McAllister, and P. Huhtanen 2003. Composition and digestive tract retention time of ruminal particles with functional specific gravity greater or less than 1.02 . J. Anim. Sci. 81:2639-2648.

Kaneto, A., K. Kosaka, and K. Nakao. 1967. Effects of stimulation of the vagus nerve on insulin secretion. Endocrinology 80:530-536.

Khiaosa-ard, R., and Q. Zebeli. 2013. Meta-analysis of the effects of essential oils and their bioactive compounds on rumen fermentation characteristics and feed efficiency in ruminants. J. Anim. Sci. 91:1819-1830.

Klevenhusen, F., A. Muro-Reyes, R. Khiaosa-ard, B. U. Metzler-Zebeli, and Q. Zebeli. 2012. A meta-analysis of effects of chemical composition of incubated diet and bioactive compounds on in vitro ruminal fermentation. Anim. Feed Sci. Technol. 176:61-69.

Kuo, C. H., S. H. Lee, K. M. Chen, C. K. Lii, and C. T. Liu. 2011. Effect of garlic oil on neutrophil infiltration in the small intestine of endotoxin-injected rats and its association with levels of soluble and cellular adhesion molecules. J. Agric. Food Chem. 59:77177725 .

Lambert, J. D., and R. J. Elias. 2010. The antioxidant and pro-oxidant activities of green tea polyphenols: A role in cancer prevention. Arch. Biochem. Biophys. 501:65-72.

Lee, S. H., H. S. Lillehoj, S. I. Jang, K. W. Lee, D. Bravo, and E. P. Lillehoj. 2011. Effects of dietary supplementation with phytonutrients on vaccine-stimulated immunity against infection with Eimeria tenella. Vet. Parasitol. 181:97-105.

Lee, S. H., H. S. Lillehoj, S. I. Jang, E. P. Lillehoj, W. Min, and D. M. Bravo. 2013. Dietary supplementation of young broiler chickens with Capsicum and turmeric oleoresins increases resistance to necrotic enteritis. Br. J. Nutr. 110:840-847.

Liu, H. W., D. W. Zhou, and K. Li. 2013a. Effects of chestnut tannins on performance and antioxidative status of transition dairy cows. J. Dairy Sci. 96:5901-5907.

Liu, Y., M. Song, T. M. Che, J. A. Almeida, J. J. Lee, D. Bravo, C. W. Maddox, and J. E. Pettigrew. 2013b. Dietary plant extracts alleviate diarrhea and alter immune responses of weaned pigs experimentally infected with a pathogenic Escherichia coli. J. Anim. Sci. 91:5294-5306

Liu, Y., M. Song, T. M. Che, D. Bravo, and J. E. Pettigrew. 2012. Anti-inflammatory effects of several plant extracts on porcine alveolar macrophages in vitro. J. Anim. Sci. 90:2774-2783.

López-Andrés, P., G. Luciano, V. Vasta, T. M. Gibson, L. Biondi, A. Priolo, and I. Mueller-Harvey. 2013. Dietary quebracho tannins are not absorbed, but increase the antioxidant capacity of liver and plasma in sheep. Br. J. Nutr. 110:632-639.

Manjunatha, H., and K. Srinivasan. 2006. Protective effect of dietary curcumin and capsaicin on induced oxidation of low-density lipoprotein, iron-induced hepatotoxicity and carrageenan-induced inflammation in experimental rats. FEBS J. 273:4528-4537.

Masella, R., R. Di Benedetto, R. Vari, C. Filesi, and C. Giovannini. 2005. Novel mechanisms of natural antioxidant compounds in biological systems: Involvement of glutathione and glutathione-related enzymes. J. Nutr. Biochem. 16:577-586.

Mirunalini, S., G. Dhamodharan, and K. Karthishwaran. 2010. A natural wonder drug helps to prevent cancer: Garlic oil. Not. Sci. Biol. 2:14-19.

Nencini, C., G. G. Franchi, F. Cavallo, and L. Micheli. 2010. Protective effect of Allium neapolitanum Cyr. versus Allium sativum L. on acute ethanol-induced oxidative stress in rat liver. J. Med. Food 13:329-335.

Nevius, E., P. K. Srivastava, and S. Basu. 2012. Oral ingestion of capsaicin, the pungent component of chili pepper, enhances a discreet population of macrophages and confers protection from autoimmune diabetes. Mucosal Immunol. 5:76-86.

Nishiyama, T., T. Mae, H. Kishida, M. Tsukagawa, Y. Mimaki, M Kuroda, Y. Sashida, K. Takahashi, T. Kawada, K. Nakagawa, and M. Kitahara. 2005. Curcuminoids and sesquiterpenoids in turmeric (Curcuma longa L.) suppress an increase in blood glucose level in type 2 diabetic KK-Ay mice. J. Agric. Food Chem. 53:959-963.

Oh, J., D. M. Bravo, E. H. Wall, and A. N. Hristov. 2016. Rumen disappearance of capsaicin and dihydrocapsaicin in lactating dairy cows. J. Dairy Sci. 99(E-Suppl. 1):788. (Abstr.)

Oh, J., F. Giallongo, T. Frederick, J. Pate, S. Walusimbi, R. J. Elias, E. H. Wall, D. Bravo, and A. N. Hristov. 2015. Effects of dietary Capsicum oleoresin on productivity and immune responses in lactating dairy cows. J. Dairy Sci. 98:6327-6339.

Oh, J., M. Harper, F. Giallongo, E. H. Wall, D. Bravo, and A. N. Hristov. 2017a. Effects of rumen-protected Capsicum oleoresin on immune responses in dairy cows intravenously challenged with lipopolysaccharide. J. Dairy Sci. 100:1902-1913.https://doi. org/10.3168/jds.2016-11666.

Oh, J., M. Harper, F. Giallongo, E. H. Wall, D. M. Bravo, and A. N. Hristov. 2017b. Effects of rumen-protected Capsicum oleoresin on productivity and responses to a glucose tolerance test in lactating dairy cows. J. Dairy Sci. 100:1888-1901. https://doi.org/10.3168/ jds.2016-11665.

Oh, J., and A. N. Hristov. 2016. Effects of plant-derived bio-active compounds on rumen fermentation, nutrient utilization, immune response, and productivity of ruminant animals. Pages 167-186 in Medicinal and Aromatic Crops: Production, Phytochemistry, and Utilization. V. D. Jeliazkov (Zheljazkov) and C. L. Cantrell, ed. American Chemical Society Publications, Washington, DC.

Oh, J., A. N. Hristov, C. Lee, T. Cassidy, K. Heyler, G. A. Varga, J Pate, S. Walusimbi, E. Brzezicka, K. Toyokawa, J. Werner, S. S. Donkin, R. Elias, S. Dowd, and D. Bravo. 2013. Immune and production responses of dairy cows to postruminal supplementation with phytonutrients. J. Dairy Sci. 96:7830-7843.

Okada, Y., K. Tanaka, E. Sato, and H. Okajima. 2010. Kinetics and antioxidative sites of capsaicin in homogeneous solution. J. Am. Oil Chem. Soc. 87:1397-1405.

Osundiji, M. A., and M. L. Evans. 2013. Brain control of insulin and glucagon secretion. Endocrinol. Metab. Clin. North Am. 42:1-14.

Patra, A. K. 2012. Dietary Phytochemicals and Microbes. Springer, New York, NY

Patra, A. K., and J. Saxena. 2011. Exploitation of dietary tannins to improve rumen metabolism and ruminant nutrition. J. Sci. Food Agric. 91:24-37.

Pennefather, J. N., E. Patak, F. M. Pinto, and M. L. Candenas. 2004 Mammalian tachykinins and uterine smooth muscle: The challenge escalates. Eur. J. Pharmacol. 500:15-26.

Pettersson, M., and B. Ahrén. 1990. Calcitonin gene-related peptide inhibits insulin secretion studies on ion fluxes and cyclic AMP in isolated rat islets. Diabetes Res. 15:9-14.

Qin, B., K. S. Panickar, and R. A. Anderson. 2010. Cinnamon: Potential role in the prevention of insulin resistance, metabolic syndrome, and type 2 diabetes. J. Diabetes Sci. Technol. 4:685-693.

Rodríguez-Prado, M., A. Ferret, J. Zwieten, L. Gonzalez, D. Bravo, and S. Calsamiglia. 2012. Effects of dietary addition of capsicum extract on intake, water consumption, and rumen fermentation of fattening heifers fed a high-concentrate diet. J. Anim. Sci. 90:1879-1884

Salman, H., M. Bergman, H. Bessler, I. Punsky, and M. Djaldetti. 1999. Effect of a garlic derivative (alliin) on peripheral blood cell immune responses. Int. J. Immunopharmacol. 21:589-597.

Sen, S., and R. Chakraborty. 2011. The role of antioxidants in human health. Pages 1-37 in Oxidative Stress: Diagnostics, Prevention, and Therapy. Vol. 1083. S. Andreescu and M. Hepel, ed. American Chemical Society, Washington, DC. 
Senior, J. R. 2012. Alanine aminotransferase: A clinical and regulatory tool for detecting liver injury-Past, present, and future. Clin. Pharmacol. Ther. 92:332-339.

Seymour, E. M., M. R. Bennink, and S. F. Bolling. 2013. Diet-relevant phytochemical intake affects the cardiac AhR and nrf2 transcriptome and reduces heart failure in hypertensive rats. J. Nutr. Biochem. 24:1580-1586.

Sheng, X., Y. Zhang, Z. Gong, C. Huang, and Y. Q. Zang. 2008. Improved insulin resistance and lipid metabolism by cinnamon extract through activation of peroxisome proliferator-activated receptors. PPAR Res. 2008:581348.

Sordillo, L. M., and S. L. Aitken. 2009. Impact of oxidative stress on the health and immune function of dairy cattle. Vet. Immunol. Immunopathol. 128:104-109.

Stelwagen, K., E. H. Wall, and D. M. Bravo. 2016. Effect of rumenprotected capsicum on milk production in early lactating cows in a pasture-based system. J. Dairy Sci. 99(E-Suppl. 1):664. (Abstr.)

Tager, L. R., and K. M. Krause. 2011. Effects of essential oils on rumen fermentation, milk production, and feeding behavior in lactating dairy cows. J. Dairy Sci. 94:2455-2464.

Takano, F., M. Yamaguchi, S. Takada, S. Shoda, N. Yahagi, T. Takahashi, and T. Ohta. 2007. Capsicum ethanol extracts and capsaicin enhance interleukin-2 and interferon-gamma production in cultured murine Peyer's patch cells ex vivo. Life Sci. 80:1553-1563.

Tanaka, H., R. Kashiwagi, and T. Koizumi. 2013. Inhibition of calcitonin gene-related peptide (CGRP) has the potential to extend first-phase insulin secretion. Exp. Clin. Endocrinol. Diabetes 121:280-285.

Tekippe, J. A., R. Tacoma, A. N. Hristov, C. Lee, J. Oh, K. S. Heyler, T. W. Cassidy, G. A. Varga, and D. Bravo. 2013. Effect of essential oils on ruminal fermentation and lactation performance of dairy cows. J. Dairy Sci. 96:7892-7903.

Thomson, M., Z. M. Al-Amin, K. K. Al-Qattan, L. H. Shaban, and M. Ali. 2007. Anti-diabetic and hypolipidaemic properties of garlic (Allium sativum) in streptozotocin-induced diabetic rats. Int. J. Diabetes Metab. 15:108-115.

Tsuji, F., and H. Aono. 2012. Role of transient receptor potential vanilloid 1 in inflammation and autoimmune diseases. Pharmaceuticals (Basel) 5:837-852.

Tyagi, S., P. Gupta, A. S. Saini, C. Kaushal, and S. Sharma. 2011 The peroxisome proliferator-activated receptor: A family of nuclear receptors role in various diseases. J. Adv. Pharm. Technol. Res. $2: 236-240$.

van de Wall, E. H., D. X. Gram, J. H. Strubbe, A. J. Scheurink, and J. M. Koolhaas. 2005. Ablation of capsaicin-sensitive afferent nerves affects insulin response during an intravenous glucose tolerance test. Life Sci. 77:1283-1292.

van de Wall, E. H., P. Y. Wielinga, J. H. Strubbe, and G. van Dijk. 2006. Neonatal capsaicin causes compensatory adjustments to energy homeostasis in rats. Physiol. Behav. 89:115-121.

van Oosterhout, W. P., G. G. Schoonman, I. M. Garrelds, A. H. Danser, K. Y. Chan, G. M. Terwindt, M. D. Ferrari, and A. Maassen-
VanDenBrink. 2015. A human capsaicin model to quantitatively assess salivary CGRP secretion. Cephalalgia 35:675-682.

Vriens, J., B. Nilius, and R. Vennekens. 2008. Herbal compounds and toxins modulating TRP channels. Curr. Neuropharmacol. 6:79-96.

Wall, E. H., P. H. Doane, S. S. Donkin, and D. Bravo. 2014. The effects of supplementation with a blend of cinnamaldehyde and eugenol on feed intake and milk production of dairy cows. J. Dairy Sci. 97:5709-5717.

Wang, J. P., J. S. Yoo, H. D. Jang, J. H. Lee, J. H. Cho, and I. H. Kim. 2011. Effect of dietary fermented garlic by Weissella koreensis powder on growth performance, blood characteristics, and immune response of growing pigs challenged with Escherichia coli lipopolysaccharide. J. Anim. Sci. 89:2123-2131.

Weiss, D. J., and K. J. Wardrop. 2010. Schalm's Veterinary Hematology. 6th ed. Blackwell, Ames, IA

Xun, W., L. Shi, H. Zhou, G. Hou, T. Cao, and C. Zhao. 2015. Effects of curcumin on growth performance, jejunal mucosal membrane integrity, morphology and immune status in weaned piglets challenged with enterotoxigenic Escherichia coli. Int. Immunopharmacol. 27:46-52.

Yang, W. Z., B. N. Ametaj, C. Benchaar, M. L. He, and K. A Beauchemin. 2010. Cinnamaldehyde in feedlot cattle diets: Intake, growth performance, carcass characteristics, and blood metabolites. J. Anim. Sci. 88:1082-1092.

Yang, W. Z., C. Benchaar, B. N. Ametaj, A. V. Chaves, M. L. He, and T. A. McAllister. 2007. Effects of garlic and juniper berry essential oils on ruminal fermentation and on the site and extent of digestion in lactating cows. J. Dairy Sci. 90:5671-5681.

Yesilbag, D., H. Biricik, I. Cetin, C. Kara, Y. Meral, S. S. Cengiz, A. Orman, and D. Udum. 2016. Effects of juniper essential oil on growth performance, some rumen protozoa, rumen fermentation and antioxidant blood enzyme parameters of growing Saanen kids. J. Anim. Physiol. Anim. Nutr. (Berl.) https://doi.org/10.1111/ jpn. 12560 .

Zeng, Z., S. Zhang, H. Wang, and X. Piao. 2015. Essential oil and aromatic plants as feed additives in non-ruminant nutrition: A review. J. Anim. Sci. Biotechnol. 6:7 https://doi.org/10.1186/s40104-0150004-5.

Zhao, F. Q., and A. F. Keating. 2007. Expression and regulation of glucose transporters in the bovine mammary gland. J. Dairy Sci. 90(Suppl. 1):E76-E86.

Zhong, R., W. Xiao, G. Ren, D. Zhou, C. Tan, Z. Tan, X. Han, S. Tang, C. Zhou, and M. Wang. 2011. Dietary tea catechin inclusion changes plasma biochemical parameters, hormone concentrations and glutathione redox status in goats. Asian-australas. J. Anim. Sci. 24:1681-1689.

Zimmerman, B. J., D. C. Anderson, and D. N. Granger. 1992. Neuropeptides promote neutrophil adherence to endothelial cell monolayers. Am. J. Physiol. 263:G678-G682. 